\title{
LIVROS COMO ESTÍMULOS E/OU DISPARADORES: POSSIBILIDADES DA DRAMATURGIA INFANTOJUVENIL BRASILEIRA NA ATUALIDADE
}

\author{
BOOKS LIKE STIMULATIONS AND/OR TRIGGERS: \\ POSSIBILITIES OF BRAZILIAN THEATRICAL TEXT FOR \\ CHILD AND YOUTH IN CURRENT DAY
}

\author{
Lucas de Carvalho Larcher Pinto*
}

\begin{abstract}
Resumo: Neste artigo, discorro sobre parte de minha pesquisa de doutorado em Artes, em desenvolvimento na Universidade Estadual Paulista (UNESP). A partir da contextualização do uso de livros infantojuvenis como estímulos e/ou disparadores no Teatro Infantojuvenil brasileiro e de apontamentos acerca das tipologias e das particularidades das obras que vêm sendo utilizadas para este fim, pormenorizo alguns aspectos de dois livros que deram origem aos espetáculos paulistanos elencados em minha investigação como focos de atenção, observação, análise e reflexão. Trata-se, portanto, de uma tentativa de contribuir para o entendimento das diversas possibilidades da dramaturgia infantojuvenil brasileira na atualidade, assim como de suas recorrências e tendências, a partir do uso de livros como elementos capazes de estimular, disparar e direcionar a criação de obras teatrais a partir das linguagens verbal e/ou não-verbal... ou (palavras,) imagens e design.
\end{abstract}

Palavras-chave: Teatro Infantojuvenil. Livros Infantojuvenis. Dramaturgia para crianças e jovens.

\begin{abstract}
In this article, I discuss part of my PhD research in Arts, in development at Universidade Estadual Paulista (UNESP). Based on the contextualization of the use of books for child and youth as stimuli and/or triggers in the Brazilian theater for child and youth and notes on the typologies and particularities of the books that have been used for this purpose, I detail some aspects about two books that gave rise to São Paulo shows in my investigation as foci of attention, observation, analysis and reflection. It is, therefore, an attempt to contribute to the understanding of the various possibilities of Brazilian theatrical text for child and youth, as well as its recurrences and tendencies, from the use of books as elements capable of stimulating, firing and directing the creation of theatrical works based on verbal and / or nonverbal languages ... or (words,) images and design.
\end{abstract}

Keywords: Theater for child and youth. Books for child and youth. Theatrical text for child and youth.

\section{Introdução... ou "Dos começos"}

Nos últimos dez anos, tenho me debruçado em questões ligadas ao Teatro Infantojuvenil ${ }^{1}$. Neste percurso, ainda no curso de graduação em Teatro da

\footnotetext{
*Artista-docente-pesquisador e Diretor de Artes Cênicas da Universidade Federal do Espírito Santo (UFES). Doutorando em Artes pela Universidade Estadual Paulista (UNESP), Mestre em Artes pela Universidade Federal de Uberlândia (UFU), possui graduação em Teatro pela mesma instituição, - com bolsa sanduíche no exterior (CNPq-CAPES) na Universidade de Évora (UÉ), em Portugal -, e em Artes Visuais pelo Centro Universitário Claretiano de Batatais (CEUCLAR). Desenvolve trabalhos que interligam as seguintes sub-áreas: Pedagogia(s) do Teatro, Teatro de Formas Animadas e Visualidades da Cena. E-mail: lclarcher@hotmail.com

${ }^{1}$ Terminologia que designa uma categoria complexa, expandida e dilatada, de diferentes práticas e/ou manifestações teatrais, que acolhem as relações entre crianças, jovens e teatro, e inserem os primeiros como elementos ou componentes centrais de sua dinâmica, independente do papel que assumam. E, além
} 
Universidade Federal de Uberlândia (UFU), voltei minha atenção para a terminologia em questão, para aspectos históricos desta modalidade de práticas teatrais e/ou manifestações espetaculares, e para o uso de narrativas como texto teatral, a partir do estudo de uma amostra de espetáculos da cidade supracitada. Já no curso de mestrado, também cursado na UFU, detive-me em tópicos relacionados ao modo como vêm sendo caracterizadas e estruturadas as encenações atuais dirigidas a crianças e jovens, tendo como pano de fundo os meandros e os desdobramentos da criação de um espetáculo infantojuvenil em que trabalhava como ator, e que partia de um texto escrito originalmente para teatro.

Nesta mesma época, realizei o estágio de docência na graduação, assumindo o papel de professor da disciplina Tópicos Especiais em Teatro Infantojuvenil, também na graduação em Teatro da UFU. Nesta experiência de ensino-aprendizagem e criação, e em outras oficinas ministradas por mim no mesmo período, comecei a me utilizar de livros infantojuvenis como estímulos e/ou disparadores ${ }^{2}$ para processos criativos voltados para crianças e jovens. Ideia advinda de algumas observações realizadas no âmbito de minha pesquisa daquele momento, em que tomei ciência de um número significativo de produções teatrais que vêm se destacando ao usarem livros infantojuvenis como indutores para criações, influenciando sua estética visual.

Tal utilização continuou a ser investigada por mim posteriormente, uma vez que, ao concluir o curso de mestrado, acabei sendo aprovado no processo seletivo para professor substituto da universidade na qual fui estudante. Como artista-docentepesquisador da instituição por dois anos, ministrei disciplinas em que sempre acabava tratando do universo do Teatro Infantojuvenil, em especial aquele advindo de estímulos e/ou disparadores de natureza não-verbal. Logo, passei a enxergar meu espaço de trabalho como um possível e instigante espaço de criação e de experimentação, no qual os elementos acima puderam ser pormenorizados, e em que muitas interrogações emergiram.

Em decorrência da minha atuação profissional na UFU, resolvi que era preciso estudar um pouco mais questões que vinham me instigando desde meados do curso de mestrado, dando continuidade às minhas pesquisas sobre o Teatro Infantojuvenil. Ao formular meu projeto de doutorado, não tive dúvidas de que desejava investigar o uso de livros infantojuvenis como estímulos e/ou disparadores para criações teatrais voltadas para o público infantojuvenil, e sua transposição para a cena, por meio de seus aspectos visuais - cenografia, iluminação, figurinos, maquiagem etc.

Hoje, como estudante da Pós-graduação em Artes da Universidade Estadual Paulista (UNESP) e Diretor de Artes Cênicas da Universidade Federal do Espírito Santo (UFES), venho desenvolvendo atividades de ensino-aprendizagem, pesquisa e extensão decorrentes do vivido até então, que, unidas à minha formação em Artes Visuais ${ }^{3}$, focalizam a formulação de discursos visuais sobre as infâncias e as juventudes ${ }^{4}$

disso, dissolve as fronteiras entre faixas etárias e categoriais sociais, fundindo, por isso, as infâncias e as juventudes em sua grafia.

2 Neste trabalho, utilizo-me dos termos estímulos e/ou disparadores para referenciar materiais, em especial os livros, que incitam, impulsionam, motivam e/ou instigam a elaboração de outras obras de arte, aqui as peças teatrais.

${ }^{3}$ Segunda graduação, cursada no Centro Universitário Claretiano de Batatais (CEUCLAR).

${ }^{4}$ Embora utilize mais à frente as terminologias "infância" e "juventude" no singular, neste artigo, opto, muitas vezes, por utilizar os termos "infâncias" e "juventudes" no plural, reportando às multiplicidades destas categorias sociais. 
expressos na cena por diferentes criadores, em espetáculos originados de livros infantojuvenis, na cidade de São Paulo, nas últimas décadas.

Deste modo, tendo em vista a natureza e as limitações de um artigo acadêmico, no presente texto, contextualizo, mesmo que em linhas gerais, o uso de livros infantojuvenis como estímulos e/ou disparadores no Teatro Infantojuvenil dos últimos anos, como também as tipologias e as particularidades dos livros que vêm sendo utilizados no âmbito paulistano. Além disso, pormenorizo alguns aspectos acerca de dois livros que deram origem aos espetáculos elencados em minha pesquisa como focos de atenção, observação, análise e reflexão. Uma tentativa de contribuir para o entendimento da multiplicidade da dramaturgia infantojuvenil na atualidade - assunto a ser destrinchado e discutido no final do texto.

\section{As origens de uma tendência}

Precisar a origem do Teatro Infantojuvenil é uma tarefa quase impossível. Isso porque o surgimento desta modalidade teatral está atrelada à emergência do conceito de infância, conforme o concebemos hoje, no início da Idade Moderna. Embora saibamos que os espetáculos teatrais voltados para crianças e jovens encontram suas raízes tanto na "China, no século III a.C., onde bonequeiros mambembes apresentavam espetáculos domiciliares para crianças e mulheres de classe social elevada" (LOMARDO, 1994, p. 11), quanto na Commedia dell'arte, temos clareza que foi somente no século XVIII que o Teatro Infantojuvenil pôde se desenvolver, a partir da consolidação da infância como uma época tranquila, protegida, e diferenciada da vida adulta.

Deste modo, o primeiro espetáculo formalmente dirigido ao público infantojuvenil data de 1781, com apresentação no Palais Royal em Versalhes, na França. Trata-se do Spectacle des Enfants, um Teatro de Sombras de Dominique Séraphin, sombrista que entusiasmou a corte, e que oferecia às crianças uma atividade que ao mesmo tempo as preparava para agir no mundo no qual estavam inseridas, e as mantinha protegidas no seio da família.

No contexto brasileiro, o Teatro Infantojuvenil de cunho artístico nasce com a peça O Casaco Encantado (1948), de autoria de Lúcia Benedetti, e se desenvolve a partir da década de 1950 do século passado através de figuras como Maria Clara Machado, Júlio Gouveia, Tatiana Belinky, Olga Reverbel, Sylvia Orthof, Vladimir Capella e Ilo Krugli - escritores, diretores e educadores célebres até os dias de hoje -, por exemplo. Este último foi responsável pela autoria e pela direção do espetáculo História de Lenços e Ventos (1974): um marco que redefiniu a forma de se pensar e fazer teatro para/por/com crianças e jovens em nosso país.

Ingrid Dormien Koudela, em seu livro Jogos Teatrais (2001), dedica um capítulo da obra para a aproximação dos espetáculos voltados para crianças e jovens com a metodologia dos jogos teatrais, destacando as transformações sofridas pelo teatro voltado para as jovens gerações no contexto nacional a partir da década de 1970. Para ela, o Teatro Infantojuvenil brasileiro passou a ser caracterizado pela exploração da teatralidade, através de espetáculos que rompiam com o ilusionismo teatral, explorando diversos recursos cênicos que se tornaram recorrentes nestas produções, permanecendo até a atualidade. 
Além disso, digo que esta mesma década foi importante para a construção de bases para um Teatro Infantojuvenil não mais pautado no didatismo ou na transmissão doutrinária de conteúdos e valores morais, mas, sim, em um pensamento artístico que pode ser um espaço para reflexão sobre a(s) condição(ões) pessoal(is) dos artistas e dos espectadores, como também possibilitar questionamentos sobre o mundo que nos cerca.

Já a década subsequente foi marcada, no contexto da produção teatral infantojuvenil brasileira, pela chegada de uma das mais importantes contribuições em sua história. Trata-se da publicação do livro A Psicanálise dos Contos de Fadas (1980), do terapeuta Bruno Bettelheim, que colaborou para a retomada dos contos de fadas como ponto de partida para criações cênicas, já que aqueles, ao mesmo tempo que traziam um legado de instruções morais e de orientações para a ordem, permitiam vislumbres de mudança de comportamentos sociais - algo extremamente significativo em tempos ditatoriais. Naquele período, o Teatro Infantojuvenil passou a se utilizar cada vez mais dos textos narrativos como textos teatrais, introduzindo o(s) narrador(es) em cena, e explorando os recursos cênicos que caracterizaram os espetáculos da década de 1970. Dentre eles, destaca-se o aproveitamento do texto narrativo em seu conteúdo original, evitando-se adaptações.

Tendo investigado esta questão durante minhas pesquisas descritas anteriormente, atentei- me para o fato de que para além da utilização da narrativa como texto teatral, nos últimos anos, em alguns casos, o objeto no qual esta se encontra inserida vinha ganhando notoriedade como estímulo e/ou disparador para a criação de espetáculos para crianças e jovens, influenciando, por vezes, sua estética. Se, nas décadas de 1970 e de 1980, a incorporação de textos narrativos se consolidou como uma possibilidade para esta categoria de espetáculos, nos anos 2000, os livros destinados a crianças e jovens aparecem, dentre outros, como estímulos para a cena infantojuvenil em nosso país.

Esta constatação pode ser observada na produção infantojuvenil paulistana dos últimos anos, com sua identidade híbrida, na qual alguns espetáculos vêm se destacando ao utilizarem dos objetos livros como estímulos e/ou disparadores para criações, influenciando sua visualidade. Segundo as críticas especializadas de Dib Carneiro Neto $^{5}$, a título de exemplo, espetáculos como As aventuras de Bambolina (2008) e Rabisco - um cachorro perfeito (2010) da Cia. Pia Fraus em parceria com o Maracujá Laboratório de Artes, e a quadrilogia O pato, a morte e a tulipa (2011), Selma (2013), Achados e perdidos (2015) e $O$ inimigo (2017) da Cia. de Feitos figuraram como produções que seguem esta tendência.

\section{Os livros como estímulos e/ou disparadores}

Para se compreender as particularidades dos livros infantojuvenis nos dias de hoje e pensá-los como estímulos para o teatro voltado para as jovens gerações, primeiramente revisito as origens e o desenvolvimento desta espécie de artefato na sociedade ocidental. Se, conforme já visto, o teatro infantojuvenil só pode surgir como

\footnotetext{
5 Crítico de Teatro Infantojuvenil paulistano, Carneiro Neto reuniu diversos dos seus escritos das últimas décadas, principalmente os publicados na revista Crescer, nos livros Pecinha é vovozinha (2003) e Já somos grandes (2014), como também no site www.pecinhaeavovozinha.com.br, ambos utilizados como fontes neste trabalho.
} 
advento de uma concepção de infância no começo da Idade Moderna, o mesmo se deu com os livros (e a literatura) destinados às jovens gerações. Neste contexto, soma-se vulgarização do papel, a descoberta da gravura e a existência da indústria gráfica, que permitiu fabricar ou reproduzir livros. Iniciado no final da Idade Média, este processo de modernização destaca a figura de Johannes Gutenberg, que criou, em 1430, um processo dinâmico de impressão em série: a prensa móvel, abrindo caminho para publicações em massa no ocidente.

Quanto aos livros infantojuvenis, pode-se dizer que foi durante a segunda metade do século XVII, na França, em pleno poderio do rei Sol, Luís XIV, que se efetiva uma literatura para crianças e jovens, tal como ocorre com o teatro. Publicações como as de La Fontaine e as de Perrault abriram as portas deste gênero de livros e se consolidaram como pioneiras, principalmente ao inserirem ilustrações ${ }^{6}$ nos livros voltados para o público em questão.

Contudo, segundo Alan Powers, em Era uma vez uma capa (2008), foi somente na transição do século XIX para o XX que os livros infantojuvenis começaram a se configurar como os conhecemos na atualidade. Para o autor, "entre meados do século XVIII e a Primeira Guerra Mundial, houve uma enorme diversificação nos tratamentos dados ao projeto gráfico de livros para crianças e jovens, com uma inventividade que demorou a ser superada" (POWER, 2008, p. 9), atingindo seu ápice na virada para o século XX. Data desta época, ainda, o surgimento de obras destinadas às jovens gerações em que palavras e imagens atuam em justaposição, assim como o design ou as variações de constituição dos livros - como a materialidade, o formato, o tamanho, a diagramação, as palavras e as imagens, as tecnologias de impressão, os tipos de encadernação etc. - ganham importância.

Tendo em vista a contextualização histórica, mesmo que lacunar, apresentada acima, podemos depreender que até os dias de hoje, diferentes são as naturezas e as possibilidades de livros destinados às crianças e aos jovens, que, de acordo com o aspecto a ser indicado, podem ser classificadas em diferentes tipologias. Para Sophia Van der Linden, em Para ler o livro ilustrado (2006), embora em alguns países certas nomenclaturas designam com maior exatidão um gênero de livro, no contexto brasileiro elas ainda são usadas sem muito critério, dificultando maiores delimitações das produções.

Com base nas proposições indicadas pela autora, foco, neste artigo, no que ela denomina livros ilustrados e livros-imagem infantojuvenis, uma vez que são estas as tipologias a que pertencem as obras utilizadas como estímulos e/ou disparadores para as criações teatrais citadas acima, e sobre as quais tecerei algumas considerações a seguir. Os livros ilustrados são "obras em que a imagem é especialmente preponderante em relação ao texto, que aliás pode estar ausente [...]. A narrativa se faz de maneira articulada entre texto e imagens" (LINDEN, 2006, p. 24). Já os livros-imagem são uma sub-categoria dos livros ilustrados, em que não há a presença de palavras, sendo a história contada exclusivamente por meio da linguagem visual.

Assim, quando me refiro aos livros infantojuvenis como estímulos e/ou disparadores para as criações infantojuvenis, neste trabalho, abordo livros em que há a preponderância do não verbal e/ou em que o verbal e o não-verbal se articulam para

\footnotetext{
${ }^{6}$ Cabe aqui destacar que, diferentemente do senso comum, ilustrações não são sinônimos de desenhos. Estes são apenas uma das possibilidades de representações gráficas e imagéticas abarcadas pelo termo. Pinturas, colagens, fotografias, entre outras, são algumas das técnicas possíveis.
} 
construção de histórias - e não, simplesmente, a quaisquer livros. Isto, já que poderiam ser constituídos apenas pelo discurso verbal narrativo ou com ênfase neste, já usado e estudado no contexto teatral, a partir, principalmente, da tendência dos romances em cena $^{7}$ e ator-rapsodo ${ }^{8}$, com seus expoentes no contexto nacional: Aderbal Freire Filho e Luiz Arthur Nunes, respectivamente.

A novidade observada em minha atual pesquisa e que é abordada neste ensaio se trata de compreender os livros não como suportes em que estão contidas histórias, expressas por meio do texto verbal, a serem transformadas em texto - épico ou dramático - teatral escrito e oralizado; mas sim, como elemento capaz de estimular, disparar e direcionar a criação de uma obra teatral a partir de diferentes linguagens, por vezes, indissociáveis: verbal e/ou não-verbal... ou (palavras,) imagens e design. Suas organizações materiais são distintas dos livros estudados em pesquisas de outros autores, que focaram apenas o aspecto verbal de uma obra.

\section{Dois casos: As aventuras de Bambolina e $O$ inimigo}

Tomando como critérios de seleção a pesquisa dos grupos em relação ao Teatro Infantojuvenil, a continuidade de trabalho ao longo de alguns anos, e seu reconhecimento pela crítica especializada, neste artigo, escolhi dois dos livros que geraram espetáculos mencionados anteriormente, a partir das críticas de Carneiro Neto, para elaborar algumas considerações. São eles: As aventuras de Bambolina (2006) e $O$ inimigo (2018). Sendo o primeiro um livro sem palavras criado por Michele Iacocca, publicado pela editora Ática, em 2006; e o segundo, um trabalho de Davide Cali e Serge Bloch, de 2008, publicado em no Brasil pela extinta Cosac Naify.

Acerca da primeira obra (Fig. 1 e 2), temos um livro impresso em papel couchê, em formato retangular e disposição retrato, de tamanho médio para adultos, mas que, nas mãos de uma criança, torna-se grande. Na diagramação de suas 32 páginas, há a exploração de todo o espaço por imagens e/ou ilustrações, que, por vezes, fazem referência às histórias em quadrinhos, em que diferentes quadros expressam momentos distintos da história em sequência. Sendo as ilustrações elaboradas por meio de desenhos (possivelmente) feitos em caneta nanquim e coloridos em aquarela, estas se caracterizam pela presença de uma paleta cromática vasta e por fortes traços de manualidade e/ou artesania.

Esta obra, construída (quase que) exclusivamente em linguagem não-verbal, é considerada um livro-imagem, ou seja, as ilustrações são responsáveis pela condução do leitor na narrativa e/ou na sequência de acontecimentos a serem contados pelo livro, possibilitando que diversas versões sejam elaboradas para uma mesma história. Embora o livro narre a trajetória da boneca que dá nome à obra, e que, ao ser jogada no lixo por sua dona, passa por diferentes situações de abandono e solidão até se tornar estrela de

\footnotetext{
${ }^{7}$ Prática teatral em que o texto narrativo é utilizado como texto teatral sem se transformar em texto dramático. Nela, as narrativas são oralizadas pelos atores, confundindo o presente e o passado, já que os discursos são em terceira pessoa e as ações em primeira.

${ }^{8}$ Pesquisa de procedimentos atoriais relacionados ao épico teatral, em que os intérpretes trabalham em aproximação aos rapsodos, espécie de contadores de histórias itinerantes, que transitavam entre cidades na Grécia antiga.
} 
um grupo de teatro de bonecos, muitos são os aspectos a serem criados e/ou inventados por quem se dispõe a fruir o texto imagético.

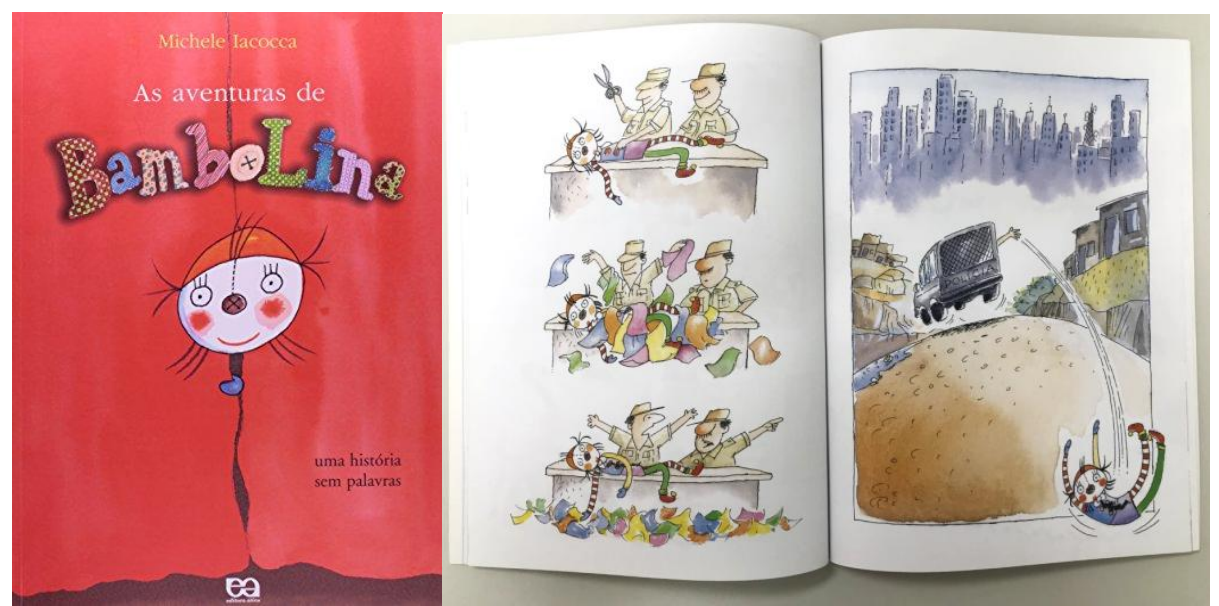

Figuras 1 e 2: Capa do livro e trecho do miolo de As aventuras de Bambolina (2006), respectivamente.

Fontes: Arquivo pessoal do autor.

A segunda obra (Fig. 3 e 4) apresenta muitas semelhanças no design com a primeira. Trata-se de um livro impresso em papel, agora do tipo Alta Alvura, em formato retangular e disposição retrato, que também se torna grande nas mãos de uma criança. Sua diagramação dispõe as imagens e/ou ilustrações no centro das 64 páginas, estando as palavras acomodadas na parte superior e/ou inferior delas. Cabe salientar, ainda, que nas páginas iniciais do livro as palavras são exploradas em suas dimensões significantes visuais de tamanho e de cor, e que as ilustrações são constituídas, em sua maioria, por desenhos realizados (possivelmente) em caneta nanquim (podendo ser esta digital), e preenchimento de cor a partir de materiais como lápis de cor, giz de cera e/ou pincel digital em poucas cores, evidenciando a interferência de recursos gráficos computacionais na constituição da obra.

Levando em consideração o fato deste livro apresentar relações de interdependência entre palavras e imagens, ele pode ser considerado um livro ilustrado, ou um exemplo de produção em que o ilustrador deixa de ser "um prestador de serviços" e torna-se co-autor, entrelaçando ainda mais as dimensões verbal e não-verbal da obra que juntas o identificam e que, sem uma delas, deixa de se constituir como tal, não permitindo, por exemplo, que as palavras sejam publicadas separadamente das imagens.

Seu enredo enfoca as relações de guerra, em que soldados de lados opostos mostram-se semelhantes em suas diretrizes de combate aos ditos inimigos, em suas fragilidades e em seus anseios. Uma provocação acerca do sentido e/ou da falta de sentido das guerras, independente do contexto em que combates acontecem, numa tentativa de desvelar as diversas facetas dos seres humanos, principalmente em situações extremas. 


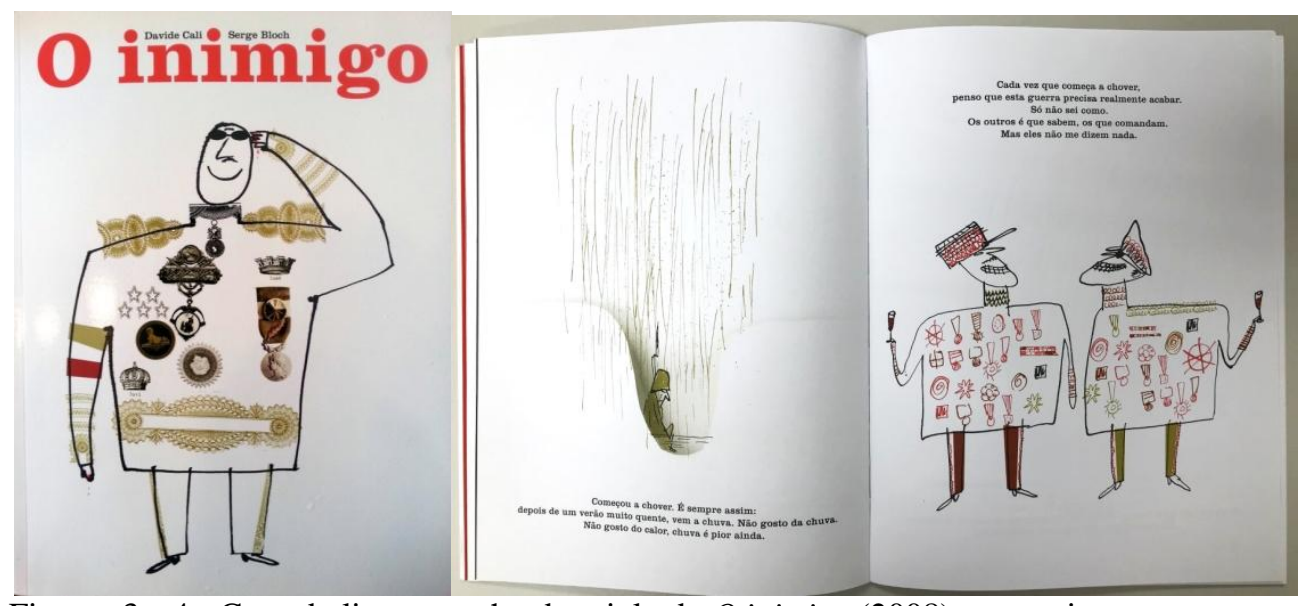

Figuras 3 e 4 - Capa do livro e trecho do miolo de $O$ inimigo (2008), respectivamente.

Fontes: Arquivo pessoal do autor.

Assim, os livros supracitados não são obras quaisquer. Eles possuem um tratamento especial de seus criadores, no que diz respeito às palavras - quando presentes -, às materialidades, aos formatos, às diagramações, às imagens etc. Há um cuidado das editoras em seus projetos como um todo. Ademais, estes livros são, por vezes, obras de tiragem baixa e com preço comercial mais elevado. Sendo obras de arte, com peculiaridades e especificidades, que retomam muitos dos aspectos inventivos dos livros criados na passagem do século XIX para o XX, parecem provocar criadores teatrais a se apoiarem nelas para, também, (trans)criarem ${ }^{9}$ propostas que apresentem modos de lidar com as infâncias e as juventudes de maneira diferente do habitual, em sintonia com paradigmas de infâncias e de juventudes contemporâneos.

Para mim, até o presente momento da pesquisa, tais livros acabam estabelecendo um profundo diálogo com as mudanças na compreensão dos modos de ser, entender e pensar as infâncias e as juventudes, principalmente a partir do fim dos anos 1980. Pautado nas ideias da Sociologia da Infância ${ }^{10}$, constato que As aventuras de Bambolina e $O$ inimigo se inserem em um contexto de mudanças nos estatutos das produções artísticas infantojuvenis, da atualidade. Ao perceber que as infâncias e as juventudes co-criam o mundo em que vivemos, entendo que cabe aos adultos um maior questionamento sobre aquilo que se apresenta para estas categorias sociais - justamente o que ocorre nas obras supracitadas por meio de seus criadores.

As histórias contadas nestes dois livros seguem, em grande parte, o tradicional esquema narrativo (de aventura), em que personagens e situação inicial são apresentados, um conflito é posto em desenvolvimento, há seu desenlace ou sua solução no clímax, e a ordem é restabelecida, com personagens e contexto inicial modificados no desfecho. Tratam-se de obras em que a existência de uma sequência de fatos, ou enredo, colaboram na elaboração de peças pautadas na estrutura narrativa evidenciada.

\footnotetext{
${ }^{9}$ Levando-se em consideração a natureza das produções teatrais infantojuvenis originadas de livros destinados a este mesmo público, em minha pesquisa, venho utilizando-me do termo (trans)criação, cunhado por Haroldo de Campos, e ampliado por mim, para me referir ao processo de transposição dos livros infantojuvenis - como objetos multifacetados - para o teatro destinado a este mesmo público.

${ }^{10}$ Campo de pesquisa interdisciplinar, cujo foco é as diferentes questões relacionadas à infância como categoria social, abarcando sua multiplicidade - daí o uso do termo infâncias em algumas partes deste texto - em diferentes contextos sociais, históricos, econômicos, culturais etc.
} 
Além disso, nesses mesmos livros, as ditas temáticas são algo que parece chamar a atenção de grupos na realização de montagens teatrais nos últimos tempos. Explicitando assuntos como guerra e abandono, estas obras tratam de tabus da sociedade ocidental, principalmente em relação às infâncias e às juventudes, com abordagens ou modos de se contar histórias sem um caráter moralizador e/ou um discurso didático. Isso é abordado por Hans-Thies Lehmann em seu artigo Das crianças, do teatro e do não-compreender (2011), ao apontar o "abandono da pretensa função didática que havia sido atribuída tradicionalmente ao teatro infantojuvenil" (LEHMANN, 2011, p. 268).

\section{A dramaturgia infantojuvenil... e Palavras finais}

Chegando ao último trecho deste artigo, e tendo em vista as questões nele abordadas, considero que minha atual pesquisa vem evidenciando, entre outras coisas, um melhor entendimento das diversas possibilidades da dramaturgia infantojuvenil brasileira na atualidade. Contudo, antes de dar prosseguimento às considerações acerca desta, julgo ser necessário retomar brevemente o conceito de dramaturgia, tal qual como o enxergo em minhas investigações, no intuito de evitar possíveis entendimentos equivocados sobre minhas próximas notas.

A partir das considerações de Patrice Pavis, em seu Dicionário de Teatro (2005), compreendo que, atualmente, a terminologia "dramaturgia" possui uma dupla acepção. Embora seja costumeiro entendê-la apenas como sinônimo de escritura verbal, aquela materializada em forma de palavras, esta também abrange a noção de escritura cênica, que leva em conta todas as possibilidades de expressão do evento teatral. Nas palavras de Pavis:

[...] a dramaturgia abrange tanto o texto de origem quanto os meios cênicos empregados pela encenação. Estudar a dramaturgia de um espetáculo é, portanto, descrever a sua fábula "em relevo", isto é, na sua representação concreta, especificar o modo teatral de mostrar e narrar um acontecimento. (PAVIS, 2005, p. 113)

Logo, quando me utilizo da expressão texto teatral - escrito e/ou oralizado -, refiro-me a textos escritos originalmente concebidos para o teatro e/ou a textos narrativos, aqueles não escritos a priori para a cena, mas que passa a ser utilizado com este fim, como nos casos da tendência dos romances em cena e ator-rapsodo. Entretanto, é preciso que estejamos atentos e desconstruamos o entendimento restrito do vocábulo "texto", revisitando sua etimologia: trama, composição, tessitura, estruturação, criação..., e suas naturezas verbal e não-verbal.

Esta revisita possibilita compreender que existe no teatro um texto próprio da cena, não construído a partir de palavras, mas sim de outras materialidades próprias da artesania teatral, tais como: a cenografia, os figurinos, a luz, os gestos etc., e conforme evidencia Pavis na citação acima. Esta acepção de dramaturgia, denominada por muitos de encenação, e, por mim, de texto cênico, é que vem me chamando atenção, na transposição de livros para a cena e na formulação de discursos visuais dos criadores teatrais.

Neste contexto, as possibilidades da dramaturgia infantojuvenil brasileira na atualidade são muitas, tanto no que diz respeito ao texto escrito e oralizado, quanto ao 
texto cênico. Este primeiro, por exemplo, conforme já dito, pode ser originalmente produzido para a cena ou não, e, ainda, pode ser gerado a priori, por um ou mais autores, sendo encenado depois ou criado simultaneamente ao texto cênico, em processos coletivizados ou não, com dinâmicas múltiplas de trabalho, além de ter como estímulos para a criação diferentes materialidades, tocando em temáticas diversas, com abordagem didática e/ou moralizadora ou não.

Já o segundo será sempre resultante de um trabalho coletivo, articulando criações de diferentes autores, ao menos que o espetáculo teatral seja uma elaboração solo, em que um único artista seja o responsável por todos os elementos da peça, inclusive estando nela como único ator. Além disso, tal como o texto teatral escrito e oralizado, o texto cênico pode partir de estímulos, tocando em temáticas mil, com abordagem didática e/ou moralizadora ou não.

No contexto brasileiro, genericamente, percebo que em ambos os textos alguns aspectos perduram e/ou são recorrentes; quais sejam: a presença de um discurso didático e/ou moralizador - mesmo que em escalas menores que as do passado, a presença de um enredo pautado no tradicional esquema narrativo (de aventura), a dificuldade em se abordar certos temas, considerados tabus, entre outros.

Contudo, nas criações paulistanas que usam dos livros como estímulos e/ou disparadores para a cena, e, sobretudo, nos casos aqui analisados, são perceptíveis modificações no quadro apresentado no parágrafo acima. Embora ainda não tenha analisado com maior afinco os processos de (trans)criações operados nos espetáculos que se originaram dos livros tratados neste artigo, descortinando seus meandros e podendo tecer considerações sobre estes ao assistir às peças preliminarmente, é notória nestas uma maneira de tratar crianças e jovens como seres humanos em suas especificidades, mas não infantilizados.

Como os livros abordados neste trabalho possuem discursos não-verbais que se destacam, os espetáculos gerados a partir deles apresentam, também, encenações em que o texto verbal, seja ele épico ou dramático, deixa de ser o elemento central. Nos espetáculos As aventuras de Bambolina e $O$ inimigo, originados daqueles, as tramas visuais ganham importância ímpar nas (trans)criações, que, por sua vez, passam a explorar aspectos imagéticos e/ou pictóricos que caracterizam, principalmente, as ilustrações dos livros que serviram como estímulos e/ou disparadores. Mas não só: estas peças têm estreita relação com os designs dos livros, explorando a dramaturgia cênica ou o texto cênico.

Assim, vislumbro na tendência aqui abordada, e sobre a qual venho me debruçando em meu doutorado, novas possibilidades para a dramaturgia infantojuvenil. Ao terem livros como pontos de partida, o teatro brasileiro para crianças e jovens, em especial o paulistano, mesmo que aos poucos, parece se aproximar da proposta apresentada acima por Lehmann... abrindo caminhos para estudos das diferentes acepções do termo dramaturgia. Até mesmo aquela não abordada neste artigo: a resultante da recepção teatral, e própria de cada espectador. Mas isto é assunto para outro texto, ou, quiçá, para futuras pesquisas... 


\section{Referências}

BETTEELHEIM, Bruno. A Psicanálise dos Contos de Fadas. Rio de janeiro: Paz e Terra, 1980.

CALI, Davide; BLOCH, Serge. O inimigo. São Paulo: Cosac Naify, 2008.

CARNEIRO NETO, Dib. Pecinha é a vovozinha. São Paulo: DBA, 2003. Já somos grandes. São Paulo: Giostri, 2014.

IACOCCA, Michele. As aventuras de Bambolina. São Paulo: Ática, 2006.

KOUDELA, Ingrid Dormien. Jogos Teatrais. São Paulo: Perspectiva, 2001.

LEHMANN, Hans-Thies. Das Crianças, do Teatro, do Não-compreender. Revista Brasileira de Estudos da Presença, Porto Alegre, v.1, n.2, p. 268-285, 2011.

LINDEN, Sophie Van der. Para ler o livro ilustrado. São Paulo: Cosac Naify, 2011.

LOMARDO, Fernando. O que é teatro infantil. São Paulo: Brasiliense, 1994.

PAVIS, Patrice. Dicionário de Teatro. São Paulo: Perspectiva, 2005.

POWER, Alan. Era uma vez uma capa. São Paulo: Cosac Naify, 2008.

Recebido em 26 de junho de 2019

Aceito em 05 de agosto de 2019 